\title{
Gestão da inovação e capacidade competitiva: uma análise não paramétrica no setor cerâmico de Campos dos Goytacazes, RJ
}

\section{(Innovation management and competitive capacity: a non-parametric analysis in the red ceramic sector of Campos dos Goytacazes, RJ, Brazil)}

\author{
A.F. Rocha, M.A.M. Palma \\ ${ }^{1}$ Laboratório de Engenharia de Produção - LEPROD, Universidade Estadual do Norte Fluminense Darcy \\ Ribeiro - UENF, Av. Alberto Lamego 2000, Parque Califórnia, Campos dos Goytacazes, RJ 28013-602 \\ af.rocha@gepro.uenf.br,mmolina@uenf.br
}

\begin{abstract}
Resumo
No atual cenário de competição acirrada, a capacidade de inovar se faz fator chave para o desempenho empresarial sendo uma fonte de obtenção de vantagens competitivas. A presente pesquisa objetivou esboçar um diagnóstico da inter-relação entre as principais variáveis de desempenho e a capacidade de inovar das empresas que trabalham no setor de cerâmica vermelha no município de Campos dos Goytacazes. Foi realizado um estudo de casos múltiplos de caráter exploratório e descritivo em cinco empresas campistas com características diferenciadas. Aplicou-se um questionário semiestruturado a profissionais das empresas ceramistas que tivessem familiaridade com o negócio. De posse dos dados obtidos na etapa inicial analisados segundo a técnica de análise de conteúdo, foi realizada uma pesquisa survey não paramétrica a fim de ratificar as informações iniciais, além de verificar relações entre conceitos. O nível de concordância entre os respondentes das 20 empresas estudadas na etapa final foi verificado através do coeficiente de concordância de Kendall. A capacidade de inovar se mostrou baixa nas empresas do setor de cerâmica vermelha de Campos dos Goytacazes. Essa deficiência provém de fatores como: mão de obra desqualificada; falta de visão inovadora; baixa cooperação interorganizacional; falta de incentivos e programas que favoreçam a inovação.
\end{abstract}

Palavras-chave: inovação, competitividade, cerâmica vermelha.

\begin{abstract}
In today's world competition, the ability to innovate can be considered essential for corporate survival and a source of competitive advantages. This research aimed to outline an inter-relationship diagnostic among the main variables of performance and the capacity to innovate in companies working in the red ceramic industry in the city of Campos dos Goytacazes, north of Rio de Janeiro State, Brazil. A multiple case studies with exploratory and descriptive purposes was carried out in five companies with different characteristics. A semi-structured questionnaire was applied to the companies' managers, people who were familiar with the business. Data collected were analyzed using content analysis in order to identify variables and factors necessary to construct a questionnaire. A survey research was conducted and these data were analyzed using nonparametric techniques to ratify the initial information, and to identify possible relationships among variables. The level of agreement among the answers furnished by the 20 companies studied was checked using Kendall concordance coefficient. The level of novelty was found low in the Campos dos Goytacazes Red Ceramic Cluster. This deficiency originate from factors such as unskilled labor, lack of innovative vision, low cooperation, lack of incentives and programs to encourage innovation.
\end{abstract}

Keywords: innovation, competitiveness, red ceramic.

\section{INTRODUÇÃO}

$\mathrm{O}$ atual contexto do mercado se caracteriza pela alta competitividade, excesso de informação, alta instabilidade, curto ciclo de vida dos produtos e concorrência acirrada, fazendo com que as empresas que vislumbrem obter êxito, tenham que desenvolver a capacidade de inovar, gerando produtos e serviços diferenciados, a fim de obter vantagens competitivas. As empresas necessitam atender, simultaneamente, às demandas por eficiência, qualidade, flexibilidade e agilidade, esta necessidade se faz realizável através da implantação de novas tecnologias [1]. Uma nova tecnologia é uma fonte de vantagem competitiva para o inovador [2]. No caso de uma tecnologia cuja implementação resulte em aumento de produtividade do processo, a empresa ganha uma vantagem em custo sobre seus concorrentes. Isto possibilita um aumento de sua margem de lucro, ao manter constante o preço de mercado, ou, ainda, a implementação de uma estratégia de penetração de mercado com a redução do preço de venda sobre seu produto. No caso de uma inovação de produto, a empresa pode ganhar um papel monopolístico através do uso de privilégios da propriedade industrial ou, ainda, ganhar o mercado pelo fato de ser a primeira a chegar a este mercado. 
Inovação engloba o processo total desde a concepção de uma idéia (invenção), passando pela manufatura do produto até seu lançamento no mercado, sendo incluso, ainda, melhoramentos ou novas estratégias na estrutura organizacional. Atividades de inovação são definidas como "todos os passos científicos, tecnológicos, organizacionais, financeiros e comerciais, incluindo os investimentos em novos conhecimentos, os quais servem atualmente ou são intencionados para a implementação de produtos e processos tecnologicamente novos ou melhorados" [3]. A capacidade de inovar de uma empresa pode ser definida como "o potencial interno para gerar novas idéias, identificar novas oportunidades no mercado e desenvolver uma inovação comercializável através dos recursos existentes e competências" [4]. A partir desta definição pode-se dizer que a capacidade de inovação de uma empresa é um construto formado pela inter-relação sinérgica de sua cultura organizacional, de seus processos internos (recursos e competências) e de suas relações interorganizacionais.

Inovações podem ser englobadas em três grandes domínios: inovações nos produtos, nos processos e organizacionais. A inovação no produto pode ser desde um produto novo introduzido no mercado cuja funcionalidade, construção técnica, características de desempenho, design e ou uso de materiais e componentes é novo ou substancialmente modificado, até um produto existente cujas características técnicas foram ampliadas ou melhoradas [5]. Ainda segundo o mesmo autor, inovação de processos se refere à adoção de um novo método de produção ou de uma melhora significativa. Estas melhoras podem envolver a introdução de novos equipamentos desenhados tanto para fazer novos produtos ou para aumentar a eficiência de um processo de produção existente e desta forma reduzir os custos. A inovação organizacional se refere à introdução de novas abordagens para gerenciar ou organizar uma empresa [6]. Nesse contexto, a capacidade de inovação se revela com elevado grau de importância para o desempenho empresarial da indústria de cerâmica vermelha de Campos dos Goytacazes. É importante ainda salientar que faz-se determinante para o sucesso empresarial o pleno conhecimento das variáveis que regem o desempenho da citada indústria, são estas: mão de obra, geração e captação de idéias, concorrência, disponibilidade de capital, tecnologia, relações interorganizacionais e apoio do governo. Porém, como as principais variáveis de desempenho influem no desenvolvimento e implementação de novas tecnologias na indústria cerâmica de Campos? Qual o impacto proveniente destas variáveis e sua relevância no desempenho da indústria cerâmica campista?

O presente estudo deseja satisfazer a dois objetivos gerais: esboçar um panorama atual da inter-relação entre as principais variáveis de desempenho e a capacidade de inovar das empresas que trabalham no setor de cerâmica vermelha no município de Campos dos Goytacazes; identificar o impacto, na indústria cerâmica, advindo das variáveis de desempenho identificadas como mais relevantes, determinando a representatividade de tais variáveis no contexto empresarial. Secundariamente serão abordados os seguintes aspectos: o impacto da inovação na vantagem competitiva; a informação para a inovação; os obstáculos para a inovação; a infraestrutura para a inovação; as características das firmas inovadoras.

\section{A indústria cerâmica no âmbito nacional}

É importante citar que as principais associações representativas do setor de cerâmica vermelha do Brasil (ABC e ANICER) possuem divergência em determinados dados pertinentes ao setor, porém, considerar-se-ão esses dados válidos no sentido que ambas as fontes convergem para evidenciar a importância do setor cerâmico no âmbito nacional.

No Brasil, as empresas cerâmicas são concentradas principalmente nas regiões Sudeste e Sul, onde se encontra maior densidade demográfica, atividade industrial mais elevada, e melhor distribuição de renda, explicando a grande concentração de indústrias do setor cerâmico na região, o que é ainda mais propício devido às facilidades de matéria prima, energia, universidades, escolas técnicas e centros de pesquisa [7]. Na Fig. 1 estão elucidados os pólos de cerâmica vermelha mais importantes das regiões Sul e Sudeste, onde estão as principais cerâmicas do país.

Porém, é relevante ressaltar que as demais regiões do país também têm se desenvolvido, principalmente o nordeste, onde diversas fábricas de variados setores industriais estão se instalando, e ainda, onde o turismo tem contribuído gradativamente para a construção de vários hotéis. A indústria da construção civil é responsável por 7,3\% do PIB nacional, o que corresponde a $\mathrm{R} \$ 126,2$ bilhões, a indústria de cerâmica vermelha contribui com $4,8 \%$ desta indústria [9]. A importância do setor de cerâmica vermelha e sua relevância no cenário brasileiro são evidenciadas pelos dados pertinentes ao setor, no qual o grande número de unidades produtoras gera,

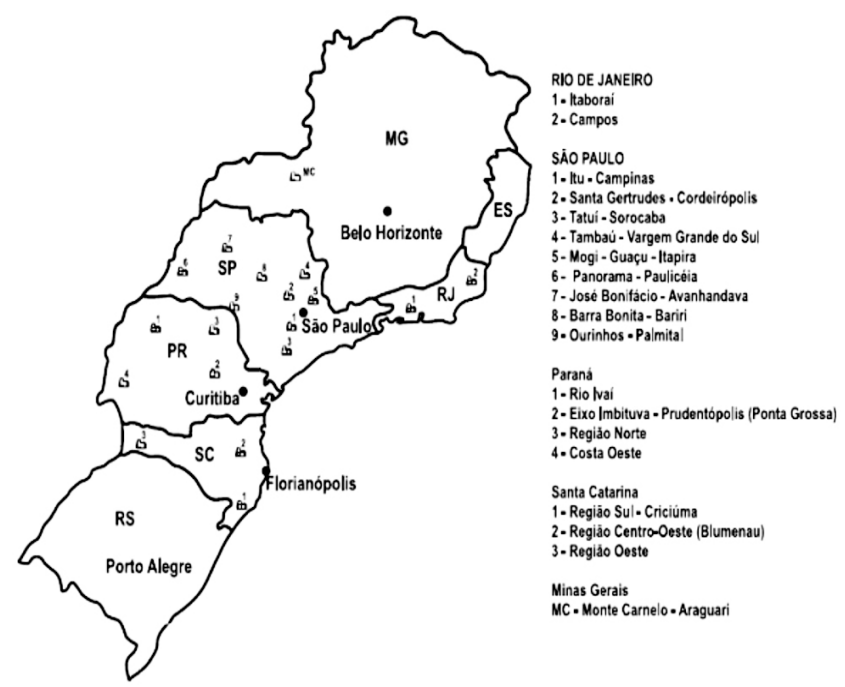

Figura 1: Principais pólos de cerâmica vermelha nos estados do Sul e Sudeste do Brasil [8].

[Figure 1: Main poles of red pottery in the South and Southeast of Brazil [8].] 
Tabela I - Dados numéricos do setor de cerâmica vermelha no Brasil [8].

[Table I - Numerical data of the red ceramic industry in Brazil [8].]

\begin{tabular}{lr}
\hline \multicolumn{2}{c}{ CERÂMICA VERMELHA } \\
\hline Número de unidades produtoras (empresas) & 7.000 \\
Número de peças/ano (bloco) & 25.224 .000 \\
Número de peças/Ano (telha) & 4.644 .000 \\
Quantidade Produzida (em massa t/ano) & 64.164 .000 \\
Matéria-prima (argilas) & 82.260 .000 \\
Produção média por empresa (peças/mês) & 365.000 \\
Faturamento (R\$ bilhões) & 4,2 \\
Empregos diretos & 214.000 \\
\hline
\end{tabular}

se tratando apenas de empregos diretos, 214.000 postos de trabalho. Tais unidades têm faturamento anual em torno de $\mathrm{R} \$ 4,2$ bilhões. Estes e outros dados do setor, levantados pela $\mathrm{ABC}$, encontram-se em destaque na Tabela I.

\section{A indústria cerâmica em Campos dos Goytacazes}

Com base no RAIS (Relatório Anual de Informações Sociais) de 2001 do Ministério do Trabalho e Emprego (2002), o setor produtivo que mais emprega mão de obra em Campos dos Goytacazes, RJ, é o setor de fabricação de produtos cerâmicos; mais especificamente, o setor de cerâmica vermelha é responsável pela alocação de aproximadamente 5.000 trabalhadores diretos e outros 25.000 indiretos, segundo o sindicado dos ceramistas de Campos. Este setor tem ainda uma importante participação na regulação do mercado de trabalho local, essencialmente no período de entressafra do setor sucroalcooleiro, empregando grande parte da mão de obra oriunda desta indústria.

A indústria da cerâmica vermelha tem elevada importância na economia do estado de Rio de Janeiro, onde o maior número de empresas, assim como o maior volume de produção do setor, cerca de 60 milhões peças/mês, está localizado em Campos dos Goytacazes. No município, o setor de cerâmica vermelha conta com aproximadamente 110 empresas, onde $40 \%$ das indústrias foram abertas na primeira metade do século $\mathrm{XX}$ e as demais foram criadas a partir dos anos 80, incentivadas pelo declínio do setor sucroalcooleiro [10]. Além do sindicato do setor, que possui 76 cerâmicas sindicalizadas, a indústria da cerâmica vermelha em Campos dos Goytacazes conta com a RCC (Rede Campos Cerâmica), que possui 13 empresas associadas. A RCC foi criada há cinco anos com o objetivo de cooperar entre si [11]. Essa inter-relação acontece, de acordo com a rede, pela troca de conhecimentos, melhoria de processos, compartilhamentos de $\mathrm{RH}$, compras, vendas, etc. A rede também desempenha importante papel ambiental na região por desenvolver a proteção ao meio ambiente através do plantio de eucaliptos.

\section{METODOLOGIA DE PESQUISA}

A presente pesquisa se valeu de duas etapas distintas. Optou-se por um estudo exploratório qualitativo (primeira etapa) sobre o setor cerâmico de Campos, já que até o momento não se tinha uma noção adequada da atual situação do setor e quais eram os elementos cruciais relacionados à inovação nas empresas do ramo. Este conhecimento era imprescindível a um estudo mais detalhado sobre o tema (segunda etapa) para evitar a introdução de variáveis espúrias na pesquisa.

\section{Primeira etapa - estudo exploratório}

Em um primeiro momento foi identificada a importância econômica e o número de empresas do setor de cerâmica vermelha de Campos dos Goytacazes para, a partir desse momento, definir a melhor abordagem às empresas. Decidiuse pela adoção da abordagem qualitativa, sendo o método de estudo de casos múltiplos a metodologia de pesquisa empírica considerada mais apropriada para este fim. Estudos preliminares qualitativos de caráter exploratório permitem a formulação de projetos mais representativos da população que possam dar subsídios, tanto para os gerentes e empresários, como para os formuladores de políticas científicas e tecnológicas, sugerindo áreas passíveis de intervenção para alavancar o desempenho da indústria. O projeto em sua etapa inicial se valeu de visitas a cinco empresas (que assim como na etapa final foram escolhidas intencionalmente segundo sua posição geográfica, selecionadas de forma a serem selecionadas empresas distantes entre si geograficamente, ou seja, em localidades distintas dentro do município pesquisado), foi aplicado um questionário semi-estruturado de caráter qualitativo a representantes que tivessem condições de responder adequadamente a questões relacionadas à empresa em geral, em especial ao aspecto tecnológico. O questionário abrangiu questões que buscavam elucidar as principais características de cada empresa (produtos, processos, forma de organização, relação com outras empresas e instituições) e, primordialmente, as principais dificuldades encontradas pelos empresários, com o objetivo de caracterizar os principais limitantes de desempenho. Após estas etapas, todo o conteúdo obtido foi analisado utilizando-se a técnica de análise de conteúdo. Através dos subsídios cedidos pelo estudo inicial foi possível elucidar as principais características e a atual capacidade de inovação das empresas ceramistas de Campos, assim como sua relação com o desempenho empresarial. Todos os dados obtidos nesta etapa foram utilizados como base para um estudo mais detalhado, no qual foi objetivado mensurar a intensidade na qual os principais aspectos explicitados, como fatores-chave na primeira fase do projeto, interferem no desempenho das empresas e na sua capacidade de inovar.

\section{Segunda etapa - pesquisa descritiva, não paramétrica}

A pesquisa, que se caracteriza em sua etapa final como 
descritiva, tem por premissa buscar a resolução de problemas através da observação, análise e descrições objetivas, isto pode ser obtido por meio de entrevistas com peritos para a padronização de técnicas e validação de conteúdo. A pesquisa descritiva se utiliza de padrões textuais como, por exemplo, questionários para identificação do conhecimento. A pesquisa tem por finalidade observar, registrar e analisar os fenômenos sem entrar no mérito de seu conteúdo. Não há interferência do investigador na pesquisa descritiva, este deve apenas procurar notar, com as devidas precauções, a intensidade e frequiência com que o fenômeno acontece. Deve ser feita uma análise completa do conteúdo obtido na pesquisa para que se chegue a uma conclusão [12]. Nesta pesquisa, além da formulação de um modelo teórico dentro de temas e conceitos já desenvolvidos em etapas anteriores, a orientação é correlacional. Busca-se determinar relações entre dois e mais conceitos, bem como o grau de relação entre estes conceitos. Este projeto procura desenvolver, esclarecer e modificar conceitos e idéias com o intuito de propiciar uma formulação mais precisa de problemas ou hipóteses de pesquisa em estudos a serem feitos posteriormente neste mesmo tema. A capacidade de inovação é um fenômeno complexo e exige profundidade nas informações necessárias à sua compreensão. Deste modo, decidiu-se pela adoção da abordagem qualitativa, através do estudo de casos múltiplos. O conhecimento prévio no tema se fez imprescindível na contribuição para aumentar a validade construída e satisfeita do conteúdo do questionário, pelo fato do mesmo ter se baseado na revisão bibliográfica e fundamentalmente na base de informações adquiridas na etapa anterior do projeto, ou seja, ter sido desenvolvido dentro de um claro referencial. Buscando a validade do constructo e de seus resultados, optou-se novamente por uma escolha padrão dos informantes, a escolha foi centrada na figura de representantes das empresas do nível gerencial que tivessem familiaridade com o negócio e, assim, condições plenas de responder o questionário elaborado. Ainda no mesmo intuito, foi garantido aos informantes não ser divulgada a sua identidade, bem como a da empresa representada. Imprimia-se assim uma maior liberdade aos respondentes, diminuindo o risco de respostas socialmente desejáveis, que são respostas dadas pelo simples receio, ou similar, de que a resposta "correta" possa de algum modo "comprometer" a empresa, ou o próprio respondente. O questionário foi aplicado diretamente a representantes de 20 empresas em visitas às mesmas. $\mathrm{O}$ preenchimento do questionário foi realizado junto ao pesquisador e, dessa forma, foi possível a explanação das questões pessoalmente aos informantes e consequientemente foi proporcionado um entendimento melhor do questionário aos representantes, o que diminui uma possível dispersão de entendimento das questões por parte dos diferentes respondentes, e assim, eleva a validade da pesquisa. O questionário proposto aos informantes compreendeu questões intrínsecas às principais variáveis de desempenho do setor, as quais também agem como limitantes de desempenho (mão de obra especializada; disponibilidade de capital; tecnologia no mercado; inovação; apoio do governo; tradicionalidade do setor; concorrência; relações interorganizacionais); tais variáveis foram inter-relacionadas às principais questões acerca da capacidade de inovar: visão inovadora na administração; inovação no produto; inovação no processo; resistência à inovação; idéias para a inovação;

\section{Pré-teste}

O pré-teste de instrumentos de pesquisa fornece subsídios para averiguar aspectos relacionados ao tipo e sequiência das questões, ambigüidade das pergunta, extensão dos instrumentos, indicação da necessidade de adicionar, eliminar ou alterar alguma questão. A realização do préteste pode ser usada inclusive a fim de mensurar o espaço de tempo durante a aplicação dos instrumentos de pesquisa [13]. Nesse estudo, foi testado um questionário preliminar em duas empresas escolhidas em função da localização geográfica com o intuito de identificar e eliminar possíveis problemas potenciais. A partir do pré-teste foram feitas modificações discretas no questionário primário, com o objetivo de melhorar a compreensão e aplicação do mesmo.

\section{Método de análise}

Desejando-se investigar a relação entre variáveis, em grande parte dos casos não se faz necessário o detalhamento englobado em uma análise multivariada. $\mathrm{Na}$ maioria dessas circunstâncias uma forma simples, porém objetiva, é satisfatória para se determinar o grau de relação entre as variáveis que se estuda. Nesses casos a utilização de técnicas estatísticas não paramétricas se apresenta como importante proposta de solução, as técnicas não paramétricas de provas de hipóteses são particularmente adaptáveis aos dados das ciências do comportamento. Tais provas chamam-se a miúdo "distribuição livre", e um de seus méritos é que, ao aplicá-las, não é necessário fazer suposições sobre a distribuição da população da qual tenham sido extraídos os dados para análise, por exemplo, se a distribuição é normal, etc. Alternativamente, tais provas são também identificadas como "provas de ordenação", e essa designação sugere outra vantagem das mesmas: as técnicas não paramétricas podem ser aplicadas a dados que não sejam exatos do ponto de vista numérico, mas que se disponham simplesmente em "postos", ou números de ordem [14]. Um dos atributos das técnicas não paramétricas é a sua aplicação a dados que não são exatos do ponto de vista numérico, mas que se organizem em números de ordem, ou "postos". O pesquisador pode determinar apenas se um indivíduo possui maior ou menor quantidade de característica, sem, no entanto, determinar numericamente quanto mais ou menos. A escolha do método se justifica no fato de que quando se deseja examinar a interação entre variáveis, a utilização de coeficientes de correlação em escala ordinal aplicada a pequenas amostras constitui um método mais indicado para a análise dos dados. O coeficiente de concordância de Kendall é um método não paramétrico que busca verificar qual o grau de associação ou correlação (concordância) entre um conjunto de 3 ou mais 
variáveis [14]. Como todo método não paramétrico, não exige pré-especificações quanto ao tipo de distribuição da população ou qualquer outro parâmetro [15,16]. Para utilizar o método, cada variável deve estar pelo menos no nível ordinal, para possibilitar a ordenação dos escores de cada variável em postos. Assim, quando se tem $\mathrm{k}$ conjuntos de postos pode-se determinar a associação entre eles utilizando o coeficiente de concordância de Kendall, W, equação A. Enquanto outras medidas de associação como o rs de spearman e o T de Kendall exprimem o grau de associação entre duas variáveis transformadas em postos, $\mathrm{W}$ exprime o grau de associação dentre $\mathrm{k}$ destas variáveis. Tal medida pode ser especialmente útil em estudos de fidedignidade relativos a julgamentos ou testes e tem também aplicações no estudo de conglomerados de variáveis, como no presente estudo [17].

$$
\mathrm{W}=\frac{\mathrm{s}}{\frac{1}{12} \mathrm{k}^{2}\left(n^{3}-n\right)}
$$

na qual $\mathrm{k}=$ número de conjunto de postos, ou número de informantes; $\mathrm{n}=$ número de variáveis colocadas em ordem; $\mathrm{s}=$ soma dos quadrados dos desvios observados a contar da média dos $\mathrm{R}_{\mathrm{j}}$, equação $\mathrm{B}$.

$$
\Sigma\left(\mathrm{R}_{\mathrm{j}}-\frac{\sum \mathrm{R}_{\mathrm{j}}}{\mathrm{n}}\right)^{2}
$$

O coeficiente de concordância $\mathrm{W}$ pode variar de $0 \mathrm{a}+1$, independentemente do número de conjunto de postagens. Isto se deve porque quando mais do que dois conjuntos de postos estão envolvidos, as ordenações não podem estar completamente em discordância [17]. Por exemplo, se um conjunto $\mathrm{X}$ está em discordância com um conjunto $\mathrm{Y}$, e também com um conjunto $\mathrm{Z}, \log$ o os conjuntos $\mathrm{Y}$ e $\mathrm{Z}$ invariavelmente estão em concordância.

Todas as informações obtidas foram também analisadas segundo a análise de conteúdo, procedimento que se justifica pelo fato de todos os questionários terem sido aplicados presencialmente nas empresas e com discussão com os respondentes acerca das questões, além das questões de caráter discursivo presentes no questionário. Na análise de conteúdo o ponto de partida é a mensagem que se é passada, mas devem ser consideradas as condições contextuais de seus feitores e se sustenta na concepção crítica e dinâmica da linguagem [18]. Não deve ser considerado apenas o que lhe é dito com o sentido exato das palavras, mas também todo o contexto gestual e implícito que pode ser percebido através das mensagens que são transmitidas pela fonte de informação. Esta técnica pode ser considerada como uma técnica de análise de dados que tem por objetivo identificar o que está sendo exposto se tratando de determinado assunto ou tema. "O que está escrito, falado, mapeado, figurativamente desenhado e/ou simbolicamente explicitado sempre será o ponto de partida para a identificação do conteúdo manifesto (seja ele explícito e/ou latente). A análise e a interpretação dos conteúdos obtidos enquadram-se na condição dos passos (ou processos) a serem seguidos. Reiterando, diríamos que para o efetivo 'caminhar neste processo', a contextualização deve ser considerada como um dos principais requisitos, e, mesmo, 'o pano de fundo' no sentido de garantir a relevância dos resultados a serem divulgados e, de preferência, socializados" [18].

\section{Limitações}

Apesar do rigor científico aplicado na pesquisa, algumas limitações devem ser explicitadas para que haja o entendimento adequado dos resultados aqui expressos e a conseqüente consideração das suas implicações. Como em qualquer trabalho de pesquisa, o presente estudo se reveste de restrições de ordem teórica e metodológica. De ordem teórica, pode-se considerar como fator limitante o fato deste trabalho não esgotar todas as variáveis pertinentes ao tema estudado. Apesar desta limitação, ambicionou-se compreender os elementos mais relevantes do contexto da pesquisa. Quanto às limitações de ordem metodológica, a utilização do instrumento de pesquisa tipo questionário implica no risco de respostas socialmente desejáveis, fato este acentuado pela atribuição da responsabilidade de fornecimento dos dados a uma só pessoa. Neste contexto, todas as informações obtidas refletem a ótica dos entrevistados em cada empresa. Dentro das limitações do trabalho, pode-se também destacar a verificação de relações pelo uso de coeficientes de correlação: "o coeficiente de correlação é um instrumento interessante e freqüentemente útil para se estudar a inter-relação entre variáveis, mas é de fidedignidade e interpretação questionáveis como instrumento quantitativo de análise destas variáveis" [14].

\section{RESULTADOS E DISCUSSÃO}

A fim de determinar a concordância global entre os respondentes das empresas pesquisadas se fez a utilização do coeficiente de concordância W de Kendall. Além de explicitar o consenso, ou falta do mesmo, entre os informantes, o coeficiente de Kendall de concordância obtém o posto médio atribuído a cada uma das variáveis estudadas, nesse caso, das variáveis que mais interferem no desempenho empresarial do setor cerâmico de Campos, as quais foram elucidadas na primeira etapa do projeto. As variáveis podem receber desde o posto " 0 " (mais importante entre as variáveis de desempenho) até o posto " 5 " (menos importante), sendo o posto médio $\mathrm{R}=2,5$. Tais dados se encontram na Tabela II.

W expressa o grau de concordância entre os 20 informantes da pesquisa quanto às suas respostas na ordenação das seis variáveis de desempenho, citadas no questionário aplicado aos mesmos. Através do coeficiente $\mathrm{W}$ podemos testar a hipótese nula $\left(\mathrm{H}_{0}\right)$ de que as $\mathrm{k}$ ordenações das variáveis de desempenho do setor cerâmico cedidas pelos informantes são independentes, a hipótese alternativa $\left(\mathrm{H}_{1}\right)$, portanto, é de que os conjuntos de ordenações são dependentes, e existe então uma concordância entre o conjunto de ordenações e, obviamente, entre os representantes das empresas, neste 
Tabela II - Resumo dos postos para as principais variáveis, atribuídos pelos informantes.

[Table II - Summary of positions for the main variables, given by the informants.]

\begin{tabular}{lccc}
\hline & $\mathrm{R}_{\mathrm{j}}$ & $\overline{\mathrm{R}}_{\mathrm{j}}$ & $\left(\mathrm{R}_{\mathrm{j}}-\Sigma \mathrm{R}_{\mathrm{j}} / \mathrm{n}\right)^{2}$ \\
\hline Mão de obra especializada & 15 & 0,75 & 1225 \\
Disponibilidade de capital & 58 & 2,90 & 64 \\
Tecnologia disponível & 77 & 3,85 & 729 \\
Concorrência & 55 & 2,75 & 25 \\
Apoio do governo & 30 & 1,50 & 400 \\
Inovação & 65 & 3,25 & 225 \\
\hline$\Sigma$ & $\mathbf{3 0 0}$ & $\mathbf{1 5 , 0 0}$ & $\mathbf{2 6 6 8}$ \\
\hline
\end{tabular}

Obs.: $R=\Sigma R i / n=2,5$

caso. Nesse método, a distribuição de $\mathrm{W}$ tem sido trabalhada e existem valores críticos tabelados. Na Tabela III se encontram valores críticos de W para os níveis $\alpha=0,05$ e $\alpha$ $=0,01$ de significância. Caso um valor de $\mathrm{W}$ observado for maior ou igual ao valor encontrado na Tabela III para um nível de significância específico, então Ho pode ser rejeitada neste nível de significância.

Por meio das fórmulas já citadas anteriormente foi possível obter o valor $\mathrm{W}=0,381$, e, comparando-se tal valor com o valor crítico de $\mathrm{W}$ (Tabela III) para $\mathrm{n}=6, \mathrm{k}=$ 20 e $\alpha=0,01$; o qual é $\mathrm{W}_{\mathrm{c}}=0,146$, encontramos um valor de $\mathrm{W}$ maior que o valor de $\mathrm{W}$ tabelado. Dessa forma, a baixa probabilidade sob $\mathrm{H}_{\mathrm{o}}$ associada ao valor encontrado de $\mathrm{W}$, nos permite rejeitar a hipótese nula, ao nível de significância $\alpha=0,01$; de que as ordenações dos informantes não estão relacionadas e, dessa forma, aceitar a hipótese alternativa $\mathrm{H}_{1}$, de que as ordenações estão relacionadas. Por conseguinte, pode-se concluir que há uma boa concordância entre os representantes das empresas questionados em suas ordenações de variáveis importantes no desempenho da indústria cerâmica, existindo assim entre os respondentes a aplicação do mesmo padrão nas informações cedidas, fato este que enaltece a veracidade dos resultados obtidos. Além disso, podemos concluir que a mão de obra e o apoio do governo são consideradas, nesta ordem, as variáveis mais importantes para o bom desempenho empresarial, na ótica dos representantes das empresas entrevistados. Quanto à eficiência, o método pode ser relacionado com a análise de variância de dois fatores de Friedman. Neste caso, a eficiência de $\mathrm{W}$ é baixa quando $\mathrm{n}=2(0,64)$, mas cresce para 0,80 quando $\mathrm{n}=5$ e para 0,955 quando $\mathrm{n}$ é grande [17]. É importante ressaltar que os resultados refletem a ótica dos representantes das empresas pesquisadas. Dentre estas (20 ao todo) 15 participam do sindicato do setor e quatro fazem parte da RCC. Após a análise do coeficiente de concordância de Kendall, pode-se validar o conteúdo das informações cedidas pelos respondentes das empresas pesquisadas, subsidiando assim a validade dos dados analisados segundo a análise de conteúdo. Análise essa explicitada a seguir, já que para tirar sentido das informações recolhidas nas entrevistas, tendo em vista que se gerou um grande volume de dados (implícitos e explícitos), faz-se aconselhável a utilização da técnica de análise de conteúdo. Ficou claro que o setor possui grande uniformidade no que diz respeito à situação de suas principais variáveis competitivas. Analisando as principais variáveis que interferem no desempenho empresarial da indústria cerâmica (mão de obra, participação do governo, disponibilidade de capital, tecnologia disponível, inovação, concorrência), podemos considerar que as variáveis, em cada empresa separadamente, possuem uma realidade muito parecida com a realidade do setor como um todo. Quando questionados sobre concorrentes de outras regiões, foram citadas as cerâmicas dos municípios de Itaboraí-RJ e Cachoeiro de Itapemirim-ES, porém, segundo os entrevistados, as cerâmicas campistas são mais competitivas, devido principalmente a melhor qualidade do barro encontrado na região. Ainda enquanto aos concorrentes, a maioria das empresas conhece sem grande profundidade os mesmos, não têm por estratégia conhecer as outras empresas e buscar melhoras no seu sistema

Tabela III - Valores críticos ( $\mathrm{W}_{c}$ ) para o coeficiente de concordância W de Kendall [17]. [Table III - Critical values $\left(W_{C}\right)$ for the Kendall's concordance coefficient W [17].]

\begin{tabular}{|c|c|c|c|c|c|c|c|c|c|}
\hline \multirow[b]{2}{*}{$\mathbf{k}$} & \multirow[b]{2}{*}{$A$} & \multicolumn{2}{|c|}{$N=4$} & \multicolumn{2}{|c|}{$N=5$} & \multicolumn{2}{|c|}{$N=6$} & \multicolumn{2}{|c|}{$N=7$} \\
\hline & & 0,05 & 0,01 & 0,05 & $\mathbf{0 , 0 1}$ & 0,05 & $\mathbf{0 , 0 1}$ & 0,05 & $\mathbf{0 , 0 1}$ \\
\hline 3 & & - & - & 0,716 & 0,840 & 0,660 & 0,780 & 0,624 & 0,737 \\
\hline 4 & & 0,619 & 0,768 & 0,552 & 0,683 & 0,512 & 0,629 & 0,484 & 0,592 \\
\hline 5 & & 0,501 & 0,644 & 0,449 & 0,571 & 0,417 & 0,524 & 0,395 & 0,491 \\
\hline 6 & & 0,421 & 0,553 & 0,378 & 0,489 & 0,351 & 0,448 & 0,333 & 0,419 \\
\hline 8 & & 0,318 & 0,429 & 0,287 & 0,379 & 0,267 & 0,347 & 0,253 & 0,324 \\
\hline 10 & & 0,256 & 0,351 & 0,231 & 0,309 & 0,215 & 0,282 & 0,204 & 0,263 \\
\hline 15 & & 0,171 & 0,240 & 0,155 & 0,211 & 0,145 & 0,193 & 0,137 & 0,179 \\
\hline 20 & & 0,129 & 0,182 & 0,117 & 0,160 & 0,109 & 0,146 & 0,103 & 0,136 \\
\hline
\end{tabular}


produtivo. Em se tratando da maturidade do mercado, a relação oferta/demanda se mostrou sazonal, com esta variação decorrente principalmente do período chuvoso, outubro a março, no qual as dificuldades encontradas devido às chuvas constantes diminuem significativamente a oferta dos produtos cerâmicos. Apesar da falta de planejamento efetivo para este período, no qual por muitas vezes a demanda se faz maior que a oferta, duas das empresas construíram galpões para minimizar as perdas, segundo seus representantes. Já no restante do ano, o mercado não absorve toda a produção existente, se configurando assim um período no qual a produção por muitas vezes é reduzida propositalmente. Em relação às inovações no produto as empresas se mostraram altamente tradicionalistas, com raríssimas mudanças. Sobre inovações mais radicais nos produtos, um dos entrevistados afirmou ter testado um novo produto, mas, o mercado agiu como obstáculo à inovação e rejeitou o mesmo. A grande maioria dos informantes não expôs pretensão de inovar no produto brevemente. Sobre o processo, as empresas revelaram realizar modificações regularmente, entretanto, nenhuma mudança radical, ou de grande impacto foi encontrada. As mudanças consistem basicamente em aperfeiçoamento do maquinário, introdução de resíduos na mistura da argila, etc. Entretanto, todas essas modificações são acompanhadas pelo setor como um todo, assim, nenhuma empresa às introduz como um diferencial competitivo, já que são alterações realizadas sem que haja pioneirismo por parte de uma empresa ou outra.

$\mathrm{Na}$ organização, as empresas não demonstraram inovar na gestão ou nas suas estratégias e metas. O que difere de uma para outra é basicamente o modo como seus donos se organizam para administrar seus negócios. $\mathrm{O}$ estabelecimento de novos objetivos e projetos na gestão destas empresas poderiam se configurar em um diferencial competitivo a favor das mesmas, já que não é prática comum o planejamento inovativo em meio a estas. Quando indagadas sobre as dificuldades em desenvolver e implementar novas idéias, várias causas para o problema foram citadas pelos respondentes, podendo-se destacar, falta de capital para investir e falta de tecnologia. Porém, o fator limitante mais evidente, o qual foi dito e enfatizado pela maior parte dos entrevistados, é a falta de mão de obra qualificada. Nas palavras de um dos informantes "mão de obra é o maior fator limitante da cerâmica vermelha... A gente tem grande dificuldade de implementar idéias novas, até de consertar problemas dentro da cerâmica, porque eles (funcionários) não têm conhecimento". Ainda sobre mão de obra, existe certa resistência por parte dos funcionários quando se deparam com qualquer tipo de mudança, ainda que levados a resistir mais por uma questão cultural que implica oposição a todo tipo de alteração. A grande importância da mão de obra especializada, bem como sua forte correlação com a capacidade competitiva das empresas de cerâmica vermelha se faz evidente; através da multivotação ponderada ficou claro ser a mão de obra especializada a variável "mais importante" para o desempenho empresarial da indústria cerâmica, e, apesar de sua notável importância, também se pode notar uma grande insuficiência de mão de obra qualificada e até mesmo de trabalhadores sem a especialização adequada para trabalhar no setor. A respeito das relações inter-organizacionais entre as empresas do setor, existe o sindicato correspondente, como dito anteriormente, no entanto, os informantes afirmam ser muito discreta a atuação do sindicato para provocar melhorias efetivas na indústria, com pouquíssimas ações práticas. Já a RCC, traz mais benefícios para seus associados, apesar de caminhar a passos lentos segundo um de seus membros; segundo o mesmo, os maiores benefícios da rede associativa são: a compra em conjunto, pois o poder de barganha é muito maior; a contratação de funcionários, já que as empresas partilham o setor de RH; e o reflorestamento que as empresas desenvolvem. No que diz respeito ao apoio do governo para o desenvolvimento de setor, a multivotação ponderada evidencia de forma totalmente clara a percepção dos informantes à cerca da participação do governo no setor. Os respondentes foram unânimes em considerar o apoio do governo como sendo a "variável mais fraca" dentre todas estudas, todos os informantes consideraram como "inexistente" o apoio do governo para com o setor, a fim de alavancar o desempenho da indústria. Quanto à participação do governo para o incentivo a novas tecnologias, as empresas, também por unanimidade, enfatizaram o descaso do governo com o setor. Os respondentes afirmaram não haver incentivo algum para inovações tecnológicas e desenvolvimento do setor, mesmo incentivos na forma de crédito; sobre os mesmos foi possível observar que, mesmo que existam, a burocracia excessiva e o grande número de exigências e empecilhos acabam por desencorajar as empresas a buscarem mais capital para investimento na empresa. É importante ainda ressaltar que em nenhuma das empresas estudadas existe um setor ou metas específicas para a criação, desenvolvimento e/ou implantação de novas tecnologias; investimentos nesse sentido poderiam trazer resultados importantes para as empresas, e se tornar um importante diferencial competitivo para as mesmas, principalmente no longo prazo. Os informantes ordenaram os principais influenciadores de desempenho da indústria de cerâmica vermelha, em suas opiniões. A partir das sequiências geradas foram atribuídas notas (de 5 a 0), e estas foram organizadas em forma de gráfico (Fig. 2) para mais bem demonstrar a importância atribuída a cada variável. A cada variável é possível, portanto, ser atribuída desde a nota 0 (caso os 20 representantes atribuam o posto de menos importância a esta) até a nota 100 na situação inversa. Notase que a mão de obra especializada e o apoio do governo se sobressaem sobre as demais.

Através dos resultados obtidos elucidou-se a notória importância da capacitação da mão de obra e o apoio do governo para o pleno desenvolvimento do setor, as quais, apesar da importância considerável das demais, se configuram como as variáveis mais representativas no desempenho empresarial de tais empresas. Tais variáveis são também os principais fatores limitantes dos setores sucroalcooleiro e textil-vestuário de Campos do Goytacazes 


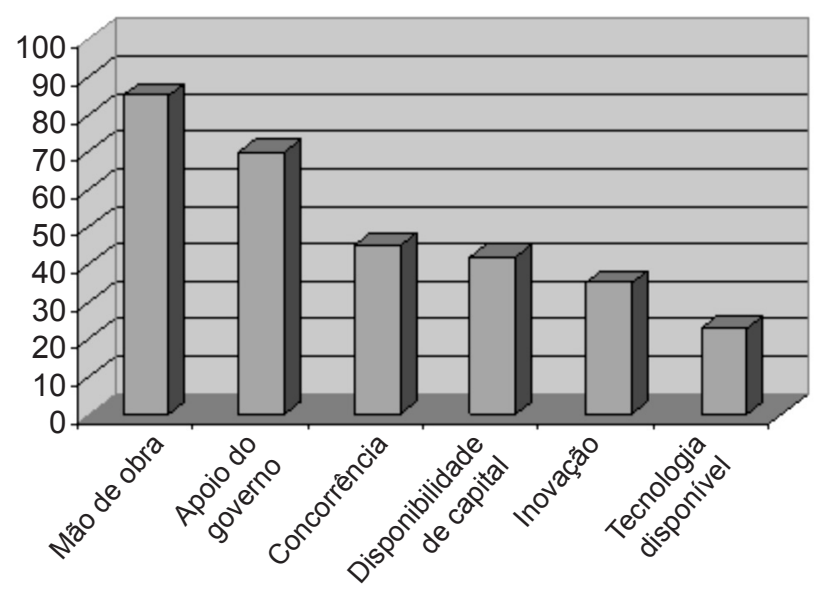

Figura 2: Nível de importância das principais variáveis de desempenho de setor cerâmico na ótica dos representantes das empresas.

[Figure 2: Importance level of key performance variables of ceramic industry in the view of theirs representatives.]

$[19,20]$, o que evidencia a extensão do problema para outros setores produtivos do município.

\section{CONSIDERAÇÕES FINAIS}

Por meio do estudo realizado, pode-se observar que no atual cenário as empresas do setor de cerâmica vermelha de Campos dos Goytacazes, RJ, possuem baixa capacidade de inovação, limitando seu desempenho empresarial, este contexto se faz presente em todos os domínios da inovação (produto, processo e organização). Tal deficiência é resultante de fatores diversos, dentre os quais se destacam: falta de profissionalização da mão de obra; falta de visão inovadora na administração das empresas; baixa cooperação interorganizacional; falta de incentivos e programas que auxiliem as empresas a buscar e investir em inovações tecnológicas. Foram reveladas algumas oportunidades de crescimento no desempenho empresarial que poderiam ser facilitadas por meio de inovações tecnológicas; sugerem-se inovações na organização visando se planejar para o período chuvoso, as quais podem caracterizar-se como importante diferencial para as empresas nesse período no qual a oferta é reduzida. Em relação à falta de qualificação da mão de obra, variável mais importante para o desempenho do setor, investimentos em treinamentos e melhor remuneração salarial, apesar do pouco capital na maior parte das empresas, são medidas consideráveis a fim de desconfigurar a mão de obra como um grande limitante para inovações na cerâmica vermelha. Cita-se ainda o impacto deste trabalho para a solicitação aos órgãos responsáveis de fomento em relação a treinamentos e demais subsídios às necessidades de mão de obra especializada para o setor, tendo em vista a importância do mesmo para o município de Campos dos Goytacazes. Estimulam-se ainda medidas de união das empresas ceramistas a fim de obter benefícios mútuos formando associações, já que associações como a RCC mostraramse eficazes para uma melhor cooperação entre as empresas.
Entretanto, é necessária a sinergia e o comprometimento para encontrar resultados reais.

Segundo o estudo, nota-se ainda que os órgãos governamentais pouco fazem em prol do desenvolvimento e aquisição de novas tecnologias para o setor de cerâmica vermelha, o apoio do governo ao desenvolvimento do setor foi explicitado como "inexistente", na ótica dos informantes. Projetos como o APL (Arranjo Produtivo Local), desenvolvido pelo Sebrae, objetivando promover a competitividade e a sustentabilidade dos micro e pequenos negócios, podem ser de grande contribuição para as empresas. Assim, há grande necessidade de se promover mudanças e projetos a fim de viabilizar a introdução de inovações tecnológicas e contribuir com o desempenho empresarial da indústria de cerâmica vermelha de Campos dos Goytacazes. Fica evidente que um setor maduro e tradicionalista (já existente e consolidado há anos na mesma região, e intimamente relacionado a costumes e/ou tradições) como o explanado na pesquisa, tende a se encontrar estagnado, com dificuldades para projetar e implementar inovações tecnológicas de forma a adquirir vantagens competitivas e otimizar o desempenho da indústria. Porém, é possível também notar que, mesmo nessas características, existem oportunidades que são passíveis de proveito através de inovações que vão desde inovações mais complexas e elaboradas que demandam trabalho árduo e alto capital para investimento, até inovações simples que dependem apenas de uma mudança de postura por parte da organização. Sobre tudo, a análise causal feita neste projeto poderá servir como base para modelos quantitativos mais elaborados que melhor identifiquem os fatores relevantes e representativos da capacidade de inovação no setor cerâmico a fim de alavancar o desempenho empresarial no setor.

\section{REFERÊNCIAS}

[1] L. F. Leite, Inovação: O Combustível do Futuro, Qualitymark, Rio de Janeiro, RJ (2005) 151 p.

[2] M. Porter, Vantagem Competitiva: Criando e Sustentando um Desempenho Superior, Ed. Campus, Rio de Janeiro, RJ (1992) $512 \mathrm{p}$.

[3] OECD, The Measurement of Scientific and Technological Activities - Proposed Standard Practice for Surveys on Research and Experimental Development - Frascati Manual, OECD, Paris, França (2002).

[4] A. Neely, J. Hii, The Innovative Capacity of Firms. Report commissioned by the Government Office for the East of England. Centre for Business Performance, Judge Institute of Management Studies, University of Cambridge, Cambridge, Inglaterra (1999).

[5] T. Andreassi, Gestão da Inovação tecnológica, Thomson Learning, S. Paulo, SP (2006) 88 p.

[6] J. C. Barbieri, A. C. T. Alvares, Inovações nas organizações empresariais, In: J. C. Barbieri, Organizações inovadoras: estudos e casos brasileiros, $2^{\mathrm{a}}$. ed., FGV editora, Rio de Janeiro, RJ (2004) 164p.

[7] ABC - Associação Brasileira de Cerâmica, Disponível 
em: http://www.abceram.org.br, 22/01/2011.

[8] L. C. Tanno, J. F. M. Motta, Cerâmica Industrial 5, 3 (2000) 37-40.

[9] ANICER - Associação Nacional Da Indústria Cerâmica, Disponível em: http://www.anicer.com.br, 22/01/2011.

[10] Agência Rio De Notícias, Notícias e Perfis dos municípios RJ, disponível em: http://www.agenciario.com/ noticias_mun.asp?cod=53499\&codMunic=75, 23/01/2011.

[11] RCC - Rede Campos Cerâmica, disponível em: http:// www.redecamposceramica.com.br, 23/01/2011.

[12] J. R. Thomas, J. K. Nelson, S. J. Silverman, Métodos de pesquisa em atividade física, $5^{\mathrm{a}} \mathrm{Ed}$., Artmed, Porto Alegre, RS (2007) 400 p.

[13] C. Selltiz, L. Wrightsman, S. Cook, L. Kidder, Métodos de pesquisa nas relações sociais, Editora Pedagógica e Universitária, S. Paulo (1987) 687 p.

[14] S. Siegel, Estatística não-paramétrica, McGraw-Hill, S. Paulo, SP (1975) 350 p.

[15] R. Hoffmann, Estatística para economistas, 4a . ed.,
Pioneira Tomson, S. Paulo, SP (2002) 432p.

[16] M. R. Spiegel, Estatística - Trad. Rev. Técnica P. Consentino, $3^{\text {a }}$. ed., Makron Books, S. Paulo, SP (1993) $643 p$.

[17] S. Siegel, Jr. Castellan, Estatística não-paramétrica para ciências do comportamento, $2^{\mathrm{a}}$ Ed., Artmed, Porto Alegre, RS (2006) 448 p.

[18] M. L. Puglisi, B. Franco, Análise de conteúdo, 2a . ed., Líber Livro, Brasília, DF (2005) 79p.

[19] A. F. Rocha, K. C. Rodrigues, M. B. Pinheiro, M. A. Molina-Palma, Inovação Tecnológica e Desempenho Empresarial: Estudo Exploratório nos Setores Maduros de Campos dos Goytacazes, RJ, XXX Enc. Nac. Eng. Produção, ABEPRO, S. Carlos, SP (2010).

[20] M. B. Pinheiro, A. F. Rocha, K. C. Rodrigues, M. A. Molina-Palma, Análise da Inovação no setor têxtil-vestuário de Campos dos Goytacazes-RJ: práticas e políticas que alavancam seu desempenho, XXIX Encontro Nacional de Engenharia de Produção, ABEPRO, Salvador (2009).

(Rec. 23/08/2011, Rev. 14/10/2011, Ac. 07/11/2011) 